\title{
MERCADO DE TRABALHO E PANDEMIA DA COVID-19: AMPLIAÇÃO DE DESIGUALDADES JÁ EXISTENTES?
}

\author{
Ana Luiza Neves de Holanda Barbosa² \\ Joana Simões Costa ${ }^{3}$ \\ Marcos Hecksher ${ }^{4}$
}

\section{INTRODUÇÃO}

É consenso que a pandemia do coronavírus (Covid-19), evento sem precedente na história recente, terá efeitos bastante expressivos e ainda pouco dimensionados sobre todos os setores da sociedade. No contexto econômico e, em particular, do mercado de trabalho, a perspectiva global é de forte recessão entre os países. A evidência empírica existente, no entanto, sugere que há uma heterogeneidade significativa do impacto da crise no que diz respeito tanto às características individuais dos trabalhadores quanto às suas posiçôes ocupacionais, contratos de trabalho e seus vínculos e contratos de trabalho (Adam-Prassl et al., 2020; Alon et al., 2020; Galasso et al., 2020).

O objetivo desta nota é identificar quais trabalhadores sofreram maior impacto em termos de perda de ocupação no Brasil em dois períodos: o mês de março de 2020 e a segunda quinzena do mesmo mês deste ano. Em particular, pretende-se desagregar as perdas ocupacionais por gênero, idade, raça/cor e nível educacional dos trabalhadores(as). A decomposição das perdas será feita, ainda, por tipos de jornadas (parcial ou integral), de emprego (com ou sem carteira assinada no setor privado) e por renda do trabalho.

A análise realizada especificamente para a segunda quinzena de março de 2020 se justifica na medida em que diversos estados e municípios passaram a restringir atividades sociais e econômicas a partir da declaração da Organização Mundial da Saúde (OMS), no dia 11 de março de 2020, de que o surto de Covid-19 se tornara uma pandemia. Nos dias subsequentes à declaração, a maior parte dos entes federativos passou a restringir atividades sociais e econômicas a fim de ampliar o distanciamento social entre indivíduos. A primeira Unidade Federativa (UF) a adotar uma medida de caráter mandatório foi o Distrito Federal (DF), no próprio dia 11 de março, quando este suspendeu a realização de eventos que envolvessem um grande número de pessoas. Desde então, o grau de restrição se ampliou rapidamente nos estados, municípios, governo federal e governos estrangeiros (Moraes, 2020)..$^{5}$

1. DOI: http://dx.doi.org/10.38116/bmt69/notastecnicas1

2. Técnica de planejamento e pesquisa na Diretoria de Estudos e Políticas Sociais (Disoc) do Ipea e professora do Instituto Brasileiro de Mercado de Capitais (IBMEC) do Rio de Janeiro.E-mail: <ana.barbosa@ipea.gov.br>.

3. Técnica de planejamento e pesquisa na Disoc/lpea.E-mail: <joana.costa @ipea.gov.br>.

4. Assessor especializado na Disoc/lpea. E-mail:<marcos.hecksher@ipea.gov.br>.

5. 0 grau de restrição se ampliou de forma continuada nos estados e nas capitais até os dias 23 e 24 de março, mantendo-se em níveis estáveis a partir de então, e, pelo menos nas semanas seguintes, raramente ocorreram recuos, ou seja, revogação de medidas de distanciamento social (Moraes, 2020). Para informações atualizadas sobre medidas de distanciamento social adotadas em cada UF em resposta à pandemia, ver a plataforma Medidas de distanciamento social e Covid-19 no Brasil. Disponível em: <https://bit.ly/2VCoyTi>. 
No que diz respeito a indicadores do mercado de trabalho para o início da pandemia e das medidas de distanciamento social no Brasil, a Pesquisa Nacional por Amostra de Domicílio (PNAD) Contínua divulga trimestralmente os microdados relativos ao trimestre anterior do calendário e, mensalmente, indicadores agregados do trimestre móvel encerrado no mês anterior. ${ }^{6}$ Quando os dados vêm agregados em trimestres, estimativas precisas de variaçóes entre meses consecutivos tornam-se impossíveis para qualquer fim e em qualquer circunstância. Só podem ser feitas as estimativas de variação entre trimestres, baseadas em mais observaçôes e com maior precisão. Vale destacar que a PNAD-Covid 19, pesquisa que objetiva estimar o número de pessoas com sintomas referidos associados à síndrome gripal e monitorar os impactos da pandemia da Covid-19 no mercado de trabalho brasileiro, dispôe de informações (mensais e semanais) somente a partir do mês de maio de 2020.

O exercício apresentado nesta nota utiliza resultados obtidos com o método proposto por Hecksher (2020a), que estima indicadores mensais (e semanais) a partir das bases de dados da PNAD Contínua. Uma das principais contribuiçôes deste trabalho, portanto, é identificar de forma precisa os efeitos no mercado de trabalho no período imediatamente após a determinação do isolamento social requerido pela chegada da pandemia ao país.

Além desta introdução, esta nota está organizada da seguinte forma: a seção 2 descreve a base de dados e a metodologia utilizada. A seção 3 analisa a perda ocupacional por gênero, idade e escolaridade. A seção 4 decompóe a perda ocupacional por jornada, formalidade e rendimento do trabalho. Por fim, a seção 5 é dedicada às consideraçóes finais. $\mathrm{O}$ apêndice apresenta uma tabela adicional, que apresenta os tamanhos das amostras utilizadas no exercício deste estudo.

\section{DADOS E METODOLOGIA}

Este estudo utiliza os dados longitudinais da PNAD Contínua produzida pelo Instituto Brasileiro de Geografia e Estatística (IBGE). No entanto, para identificar o mês (e até mesmo a quinzena) em que ocorreu a entrevista, utiliza-se a técnica descrita em Hecksher (2020).

Dessa forma, o método empregado para estimar indicadores mensais a partir da PNAD Contínua incluiu as três primeiras etapas descritas em nota técnica anterior (Hecksher, 2020). Uma quarta etapa foi adotada para desagregar os meses em quinzenas. O conjunto de quatro etapas é resumido na sequência a seguir.

1) As datas de referência possíveis foram delimitadas contrastando as datas de nascimento e idades informadas de todos os moradores de cada domicílio em todas as visitas.

2) As observações com meses identificados foram reponderadas para corrigir parte dos vieses gerados na seleção de observaçôes com meses identificáveis.

3) A partir da base de microdados reponderada, foram ajustados indicadores mensais compatíveis às séries para trimestres móveis divulgadas pelo IBGE.

6. A razão principal para a não divulgação de indicadores nem microdados desagregados de mês a mês é a de que suas oscilações, principalmente da taxa de desemprego, entre meses consecutivos não eram estatisticamente significativas (Hecksher, 2020a). 
4) No subconjunto de observaçóes cujas quinzenas também puderam ser identificadas, foi feita uma nova reponderação ancorada nas estimativas mensais ajustadas das seguintes populaçóes: i) com até 13 anos de idade; ii) fora da força de trabalho; iii) desocupada; iv) ocupada sem contribuição previdenciária; e $v$ ) ocupada com contribuição previdenciária.

A primeira etapa baseia-se no fato de que o IBGE pergunta aos respondentes da PNAD Contínua as datas de nascimento de todos os moradores de seus domicílios e, quando essa data é informada, os microdados públicos desidentificados apresentam, além delas, a idade calculada de cada pessoa na data de referência, o sábado que encerra a semana de referência (IBGE, 2018). Isso permite observar se a data de referência da entrevista foi antes ou depois de cada aniversário informado.

Esse procedimento permite identificar os meses de referência de quase $40 \%$ das observaçóes da PNAD Contínua de 2012 a 2020, mas introduz vieses, pois algumas características dos domicílios estão associadas a maior probabilidade de ter o mês identificado, o que afetaria substancialmente estimativas de interesse como o nível de ocupação. A reponderação levou em conta 96 células, definidas por: faixas de tamanho do domicílio (uma, duas, três, quatro, cinco e seis ou mais moradores); número de visitas realizadas (até quatro ou cinco; ter ou não uma pessoa do sexo masculino como responsável em mais da metade das visitas; a idade mediana da pessoa responsável ser ou náo de pelo menos 60 anos; e a escolaridade mediana da pessoa responsável ser ou não de pelo menos onze anos de estudo.

Como as séries para trimestres móveis informam a variação acumulada de diversos subgrupos da população entre qualquer dupla de meses afastados em múltiplos de três meses, os dados mensais reponderados fornecem, indiretamente, várias estimativas alternativas para o nível de sua respectiva série em qualquer mês. Para cada grupo populacional de interesse, utilizou-se a média dessas várias estimativas para os três primeiros meses de 2012. Aplicou-se entáo a relaçáo entre os três resultados encontrados e sua média para desagregar em meses os grupos populacionais estimados pelo IBGE para o primeiro trimestre de 2012. Assim, a partir das variaçóes acumuladas conhecidas, foram construídas séries mensais compatíveis com as séries oficiais de trimestres móveis.

Finalmente, os resultados mensais para cinco subgrupos da população (com até 13 anos de idade, fora da força de trabalho, desocupada, ocupada sem contribuição previdenciária e ocupada com contribuição previdenciária) foram desagregados em estimativas quinzenais compatíveis por meio de uma reponderaçáo adicional. As estimativas a seguir consideram a nova reponderação.

\section{PERDA OCUPACIONAL POR CARACTERÍSTICAS INDIVIDUAIS}

A base descrita na seção anterior possibilita ter informaçôes sobre os indivíduos ao longo do tempo, o que é relevante para compreender melhor a dinâmica de diversos indicadores. Nesta nota, o foco está em compreender as características dos indivíduos (esta seção) e dos postos de trabalho (seção seguinte) entre os trabalhadores que perderam suas ocupaçóes em decorrência da crise econômica estabelecida pelo contexto da pandemia do coronavírus. Esta análise é possível graças à observação do indivíduo em dois momentos no tempo: antes da crise (último trimestre 
de 2019) e início da crise (março de 2020 ou a última quinzena de março de 2020). Por meio dessa comparação, é possível identificar as pessoas que estavam trabalhando e as que deixaram de trabalhar, seja porque foram para fora da força de trabalho ou porque estão desempregadas.

Assim, é possível verificar quais características pessoais ou ocupacionais estão associadas a uma maior chance de perda do emprego. Além disso, tais características são contrastadas com as observadas em painéis para o período análogo de anos anteriores (2018-2019 e 2017-2018) com a finalidade de distinguir o que é específico da atual crise.

Para investigar quais características individuais estão mais associadas à perda de emprego durante a pandemia, os gráficos 1 e 2 apresentam a proporção de indivíduos que perderam o trabalho de acordo com sexo, idade, cor e escolaridade entre o último trimestre do ano $t-1$ e o mês de março do ano $t$. Os anos $t$ correspondem a 2020, 2019 e 2018. O gráfico 2, na verdade, é uma subamostra do gráfico 1 , pois considera somente as pessoas que foram entrevistadas na última quinzena do mês de março. Apesar de a amostra ficar reduzida no gráfico 2, esse é o período em que de fato se iniciaram mais medidas de isolamento. No anexo, estáo apresentados os tamanhos amostrais em cada categoria.

Em março de 2020 (gráfico 1), cerca de 15\% dos ocupados no último trimestre de 2019 perderam sua ocupação e transitaram para o desemprego ou para a inatividade econômica. Isso corresponde a 4-5 pontos percentuais (p.p.) acima do observado no período correspondente nos dois anos anteriores. Como esperado, ao considerar somente a última quinzena de março (gráfico 2), as proporçóes ficam um pouco mais elevadas. Ou seja, apesar de as mensuraçóes ocorrerem no início da crise, foi possível identificar uma elevação na probabilidade de perder o emprego.

Em ambos os gráficos, destaca-se o fato de que os grupos com maiores chances de perder o emprego no início da crise são as mulheres e os jovens, cerca de $20 \%$. No entanto, vale notar que, ao comparar com os anos anteriores, os jovens ${ }^{7}$ possuíam probabilidade bastante elevada em contraste com os adultos, e esta subiu cerca de 2 a 3 p.p. na crise. As mulheres sofreram uma elevação de 7 a 8 p.p. nas chances de perder o emprego.

Destaca-se, ainda, que há também diferenciais relevantes por cor e escolaridade. A proporção de pretos e pardos que perdem o emprego encontra-se sempre acima da média e chega a alcançar 18\% no início da crise (gráfico 2) (uma elevaçáo de 5 p.p. vis-à-vis 4 p.p. entre os brancos). Com a chegada da crise, possuir ensino médio incompleto ou menos significa uma chance de $15 \%$ de transitar para o desemprego ou para fora da força de trabalho (gráfico 2), o que corresponde a 4 p.p. em relaçáo ao ano anterior (entre aqueles com maior escolaridade, a subida foi de 3 p.p.).

Em outros termos, considerando o indicador de perda de emprego e os diferenciais associados às características individuais, observa-se que a crise econômica introduzida pela pandemia do novo coronavírus aprofundou algumas das desigualdades observadas no mercado de trabalho, pois aqueles que estavam em situaçáo desvantajosa apresentam piores indicadores. Contudo, vale ressaltar que a deterioração foi ainda maior entre as mulheres.

7. Vale notar que a probabilidade mais elevada dos jovens de transitar de uma situação de ocupação para uma de inatividade ou desemprego não necessariamente indica um contexto negativo. Há jovens que podem estar migrando para uma situação de estudo/qualificação. 
GRÁFICO 1

Perda ocupacional por características individuais $(2018-2020)^{1}$

(Em \%)

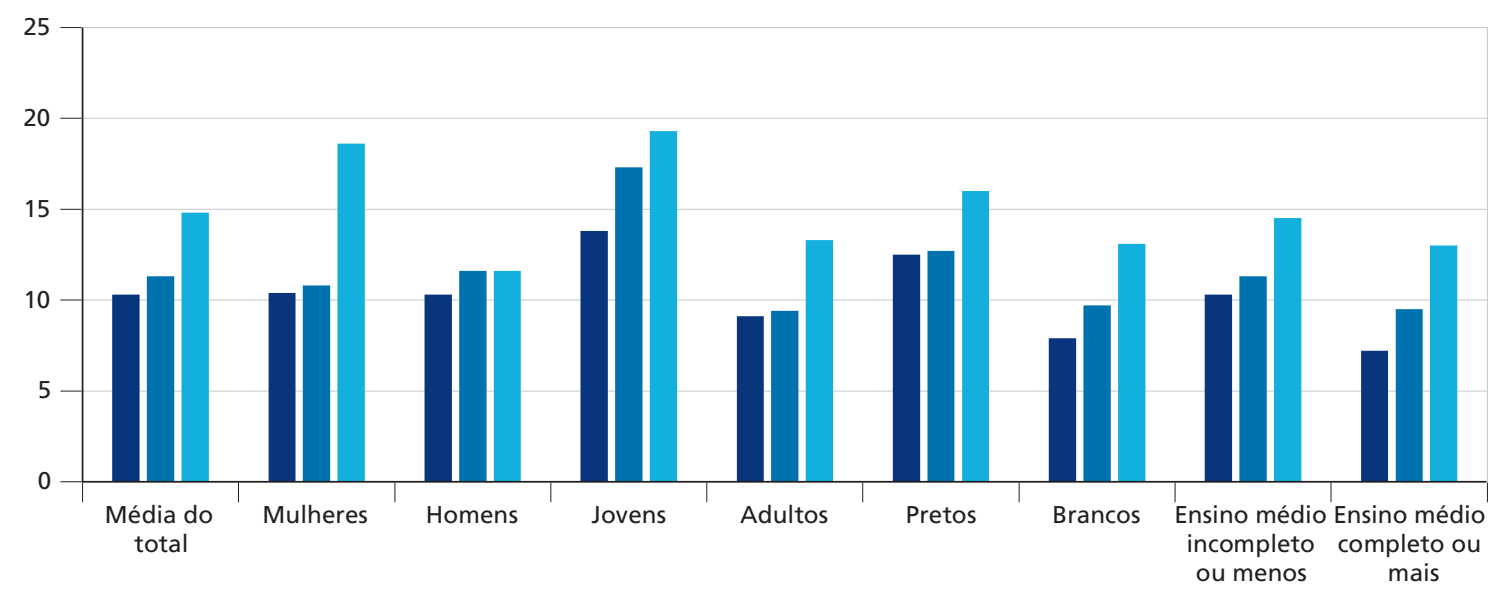

E Entre o quarto trim. de 2017 e o mês de março de 2018 Entre o quarto trim. de 2018 e o mês de março de 2019

Entre o quarto trim. de 2019 e o mês de março de 2020

Fonte: Estimativas próprias baseadas na PNAD Contínua/IBGE.

Elaboração dos autores.

Nota: ' Referência: mês de março de 2020.

\section{GRÁFICO 2}

\section{Perda ocupacional por características individuais (2018-2020) ${ }^{1}$}

(Em \%)

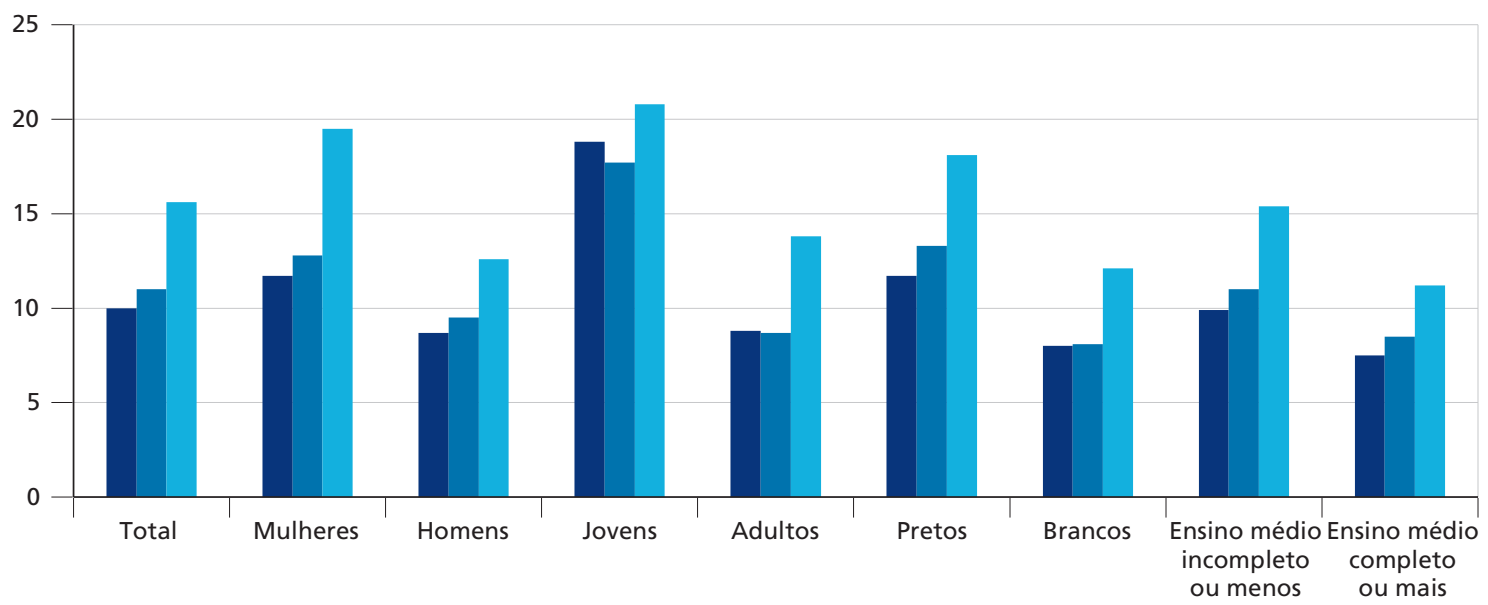

Entre o quarto trim. de 2017 e a segunda quinzena de março de 2018

Entre o quarto trim. de 2019 e a segunda quinzena de março de 2019

Entre o quarto trim. de 2019 e a segunda quinzena de março de 2020

Fonte: Estimativas próprias baseadas na PNAD Contínua/IBGE.

Elaboração dos autores.

Nota: ${ }^{1}$ Referência: segunda quinzena do mês de março de 2020. 


\section{PERDA OCUPACIONAL POR CARACTERÍSTICAS DO TRABALHO}

Os gráficos 3 e 4 a seguir complementam a seção anterior ao apresentar a proporção de trabalhadores que perderam o emprego de acordo com as características dos seus postos de trabalho. Chama a atenção que mesmo para os anos anteriores à crise, já havia diferenciais relevantes ao comparar trabalhadores empregados no setor privado com e sem carteira assinada, trabalhadores de jornada parcial e integral, e trabalhadores que pertencem ao terço inferior e o superior da distribuição de salários. Tais diferenças foram ampliadas com o início da crise, especialmente se for considerada somente a última quinzena de março. No gráfico 4 (última quinzena de março), as proporçóes de trabalhadores que perdem o emprego alcançam o patamar de $30 \%$ para aqueles que trabalham no setor privado sem carteira assinada, e para aqueles que se encontram nos estratos inferiores da distribuiçáa salarial. Mesmo se for considerado todo o mês de março (gráfico 3), estas proporçôes ficam acima de $23 \%$, e chama a atenção que a elevação desses indicadores não ocorreu de forma proporcional entre as categorias opostas.

Para os trabalhadores de jornada parcial, a proporçáo que transita para o desemprego ou inatividade também se apresenta elevada com o início da pandemia e fica no intervalo de $20 \%$ a $25 \%$. E apesar de aqueles com jornada integral também experimentarem um aumento nas chances de perder o emprego, o diferencial se mantém relevante.

Dessa forma, também as características dos postos de trabalho estáo associadas às chances de perder o emprego no início da crise. Além disso, o início da crise parece ainda aumentar o diferencial de acordo com a posse de carteira de trabalho assinada, e a posiçáo na distribuição salarial.

GRÁFICO 3

Perda ocupacional por características do trabalho (2018-2020) ${ }^{1}$ (Em \%)

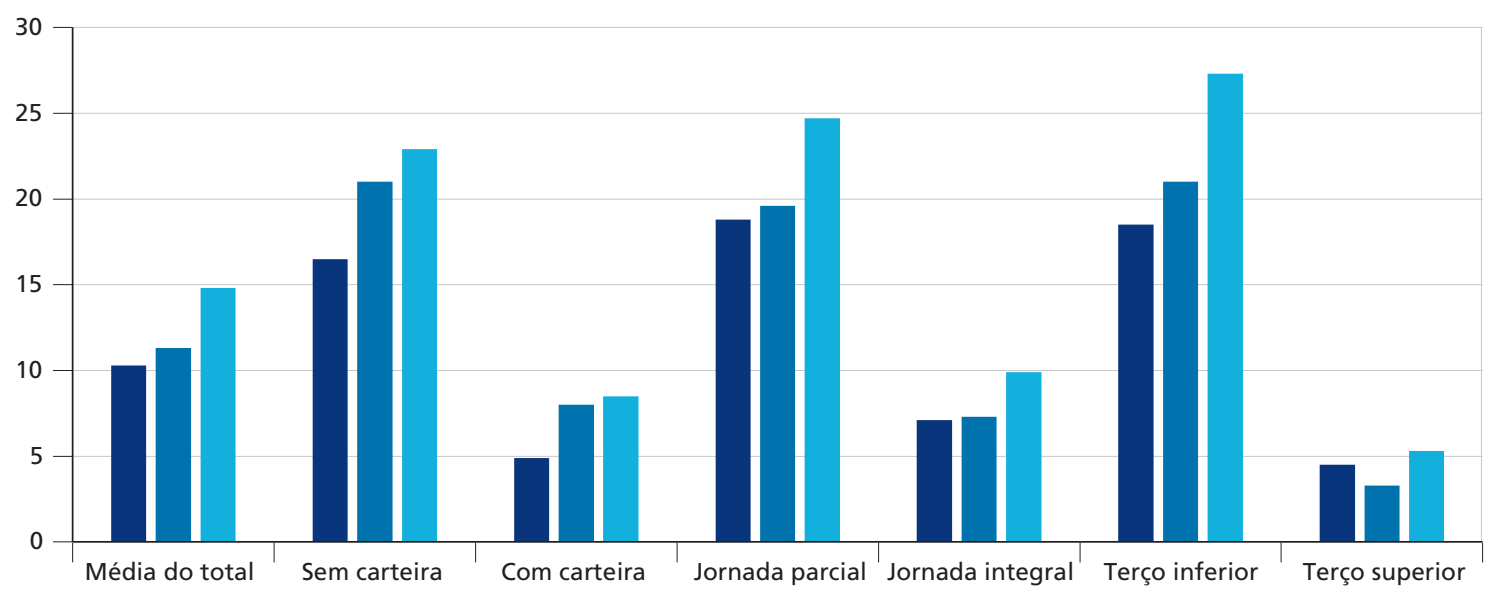

Entre o quarto trim. de 2017 e o mês de março de 2018 Entre o quarto trim. de 2019 e o mês de março de 2020

Entre o quarto trim. de 2018 e o mês de março de 2019

Fonte: Estimativas próprias baseadas na PNAD Contínua/IBGE.

Elaboração dos autores.

Nota: ${ }^{1}$ Referência: mês de março de 2020. 
GRÁFICO 4

Perda ocupacional por características do trabalho $(2018-2020)^{1}$

(Em \%)

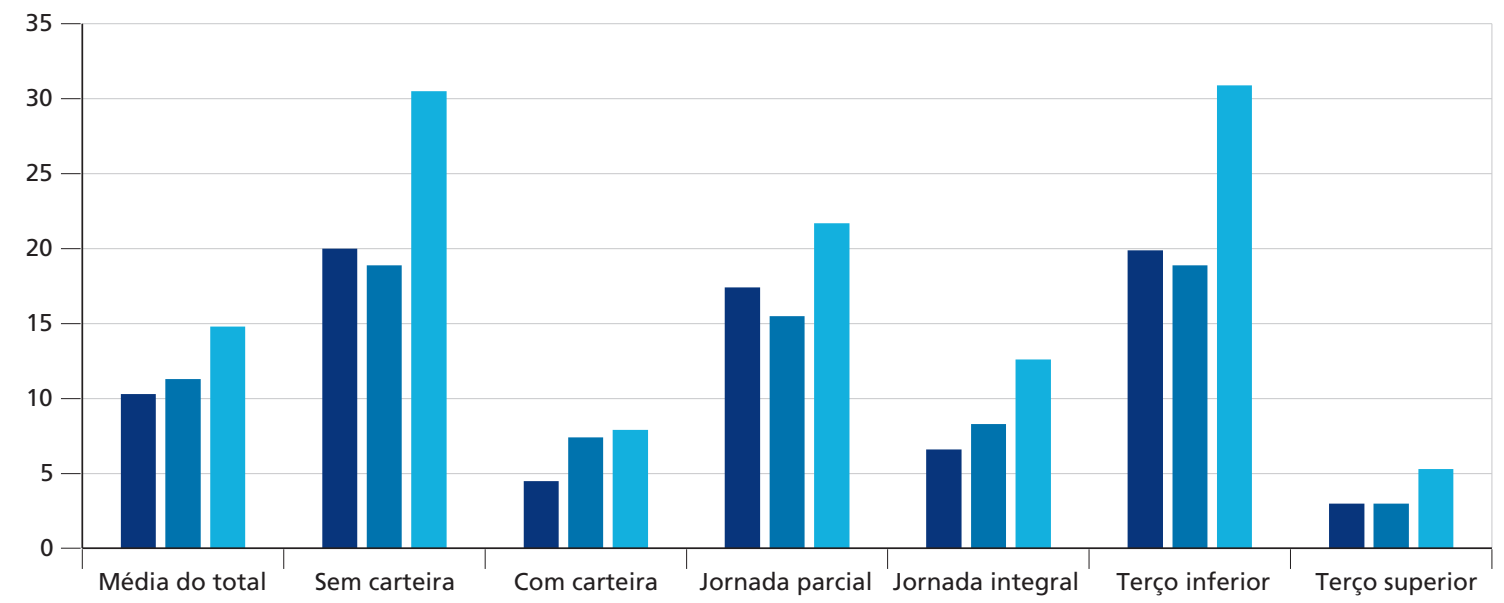

Entre o quarto trim. de 2017 e a segunda quinzena do mês de março de 2020

Entre o quarto trim. de 2018 e a segunda quinzena do mês de março de 2019

Entre o quarto trim. de 2019 e a segunda quinzena do mês de março de 2020

Fonte: Estimativas próprias baseadas na PNAD Contínua/IBGE.

Elaboração dos autores.

Nota: ${ }^{1}$ Referência: segunda quinzena do mês de março de 2020.

\section{CONSIDERAÇÕES FINAIS}

Tendo em vista a natureza da crise econômica ocasionada pela pandemia do coronavírus, era esperado observar efeitos significativos e diferenciados por trabalhador desde o início da crise. As medidas necessárias de isolamento social para o controle do contágio do Sars-COV-2 restringem prontamente a circulaçáo de trabalhadores e consumidores, o que compromete tanto a demanda por produtos quanto a oferta de trabalho.

Os trabalhadores em situação de maior precariedade no mercado de trabalho, os impossibilitados de realizar seu trabalho a distância e aqueles do setor informal da economia são os que possuem maior risco de perder a ocupação. Também as mulheres devem ser afetadas de forma diferenciada nessa crise devido à ausência de atividades escolares presenciais e ao aumento das atividades domésticas e de cuidados. De fato, os resultados encontrados nesta nota sugerem que os efeitos desta crise sobre o mercado de trabalho foram imediatos e afetaram de forma diferenciada os trabalhadores. Os mais afetados em termos de perda de ocupação foram as mulheres, os mais jovens, os pretos e os com menor nível de escolaridade. No que diz respeito aos postos de trabalho, destacam-se os trabalhadores com jornada parcial, informais e com menores salários entre os que tiveram perdas significativas. Tais resultados são corroborados pela evidência internacional sobre os efeitos da crise da pandemia da Covid-19 sobre o mercado de trabalho (Adam-Prasslr et al., 2020; Alon et al., 2020; Galasso et al., 2020). 
São várias as possíveis extensões para este estudo. A primeira delas será refinar a análise aqui apresentada de forma a entender melhor os principais determinantes das perdas de ocupação ocasionadas pela crise. Outra extensão é investigar os setores em que o trabalho pode ser realizado remotamente, em casa. Góes et al. (2020), por exemplo, estimam que 22,7\% dos empregos no Brasil podem ser realizados inteiramente em casa, com variaçóes significativas entre as diferentes UFs e os tipos de atividades ocupacionais. Uma análise mais detalhada dos setores em que a participação das mulheres é alta e dos setores que são mais vulneráveis às medidas de distanciamento social pode indicar efeitos diversos das recessóes econômicas usuais, que afetam de forma mais severa o emprego masculino.

Os desafios impostos pela crise da pandemia do coronavírus (Covid-19) são imensuráveis, dado os efeitos adversos significativos sofridos, em especial, por grupos mais vulneráveis da população. Os resultados apresentados nesta nota vêm reforçar a necessidade de respostas imediatas em termos de políticas direcionadas para estes grupos da população que são mais afetados pela crise.

\section{REFERÊNCIAS}

ADAMS-PRASSL, A. et al. Inequality in the impact of the Coronavirus schock: evidence from real time surveys. Bonn, Germany: IZA Institute of Labor Economics, Apr. 2020. (IZA Discussion Paper, n. 13183).

ALON, T. M. et al. The impact of Covid-19 on gender equality. Stanford, California: NBER Working Paper Series, Apr. 2020. (Working Paper, n. 26947).

GALASSO, V. et al. Gender differences in Covid-19 related attitudes and behavior: evidence from a panel survey in eight OECD countires. Stanford, California: NBER Working Paper Series, June 2020. (Working Paper, n. 27359).

GÓES, G. S.; MARTINS, F. S.; NASCIMENTO, J. A. S. Potencial de teletrabalho na pandemia: um retrato no Brasil e no mundo. Carta de Conjuntura, n. 47, 2020.

HECKSHER, M. Valor impreciso por mês exato: microdados e indicadores mensais baseados na PNAD Contínua. Brasília: Ipea, abr. 2020a (Nota Técnica, n. 62).

. Mercado de trabalho: a queda da segunda quinzena de março, aprofundada em abril. Brasília: Ipea, 2020b. (Nota Técnica, n. 47).

IBGE - INSTITUTO BRASILEIRO DE GEOGRAFIA E ESTATÍSTICA. Pesquisa Nacional por Amostra de Domicílios Contínua. Notas técnicas - Versáo 1.5. Rio de Janeiro: IBGE, 2018.

MORAES, R. F. Índices de medidas legais de distanciamento social. Brasília: Ipea, 2020. Disponível em: <https://bit.ly/3ig5Qe5>. 


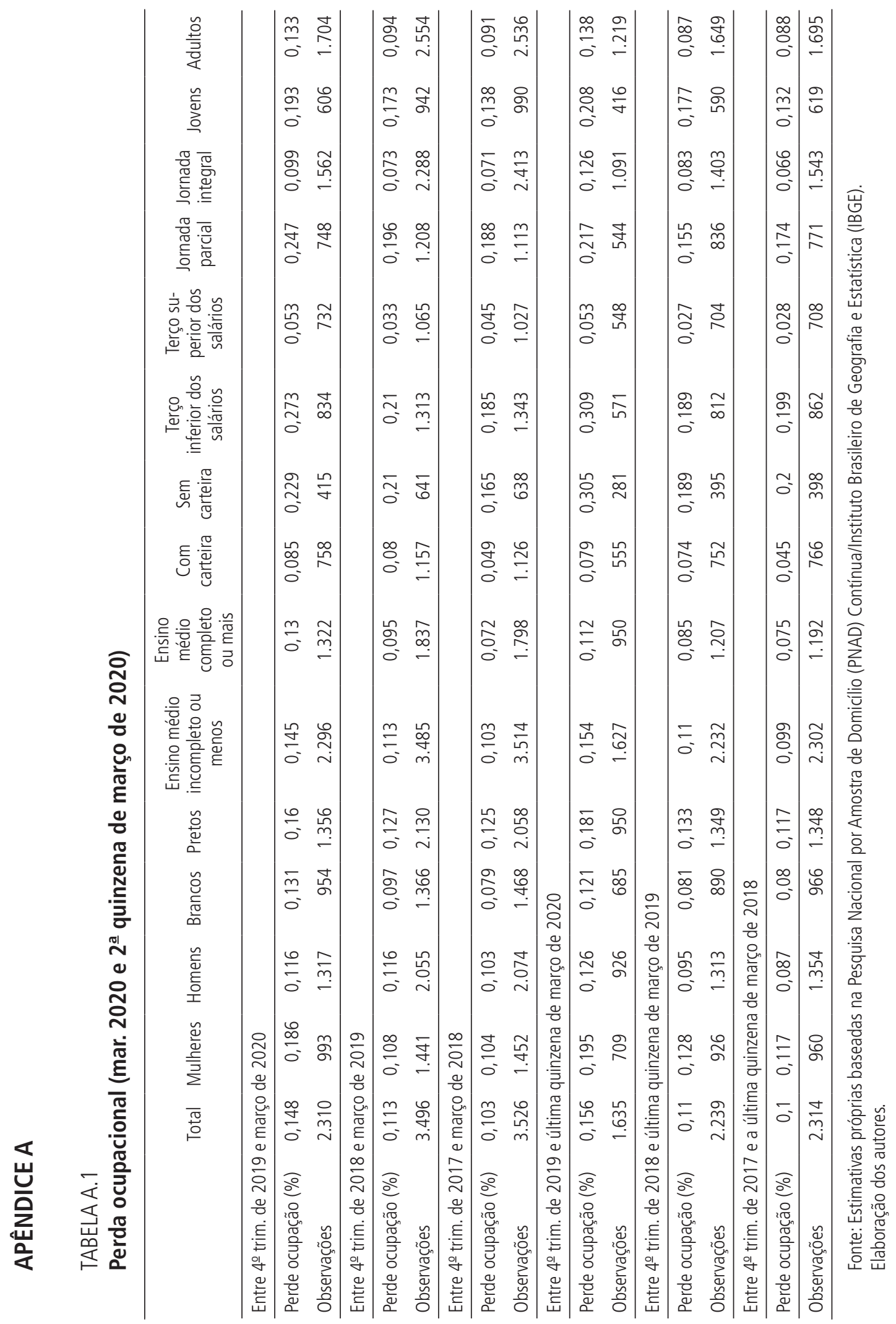


